\title{
Concentrations of volatile organic compounds (VOC) after home renovations in terms of hygiene and environmental health
}

\author{
O. Herbarth ${ }^{1} \&$ S. Matysik ${ }^{2}$ \\ ${ }^{1}$ University Leipzig, Faculty of Medicine, \\ Institute of Environmental Medicine and Hygiene, Leipzig, Germany \\ ${ }^{2}$ University Hospital Regensburg, Institute of Clinical Chemistry and \\ Laboratory Medicine, Regensburg, Germany
}

\begin{abstract}
Potential health relevant indoor exposures are volatile organic compounds (VOC) which are particularly high after renovation activities.

Objectives: The main aim is the determination of the concentration-time-curve after renovation, and from that the derivation of the time span which has to be waited for until the indoor pollution reaches a reference level.

Methods: 26 VOC are selected as part of a VOC-panel which is usually measured to characterize the quality of the indoor air. The decrease in the concentrations after renovations was assessed under real-life situations. Within the first 30 days after renovation VOC were active sampled on 11 different days. As part of an epidemiologic study, the same VOC were passively sampled monthly in 243 homes. GCMS was used to determine the VOC-concentration. An exponential function was used to interpret the concentration decay.

Results: The average time range which has to elapse following renovation before a guideline or reference value is reached was between 2 and 8 weeks dependent on the underlying reference value.

Conclusions: From the point of prevention this waiting time should at least be applicable to public buildings, and institutions (especially relevant in cases of nurseries, playschools etc.) and in the end to private homes as well to avoid negative health or well being consequences.
\end{abstract}

Keywords: indoor exposure, VOC, renovation, waiting period, hygiene, environmental medicine. 


\section{Introduction}

Volatile organic compounds (VOC) play an important role in the indoor air quality (Molhave et al. [1]). The main indoor sources are new furnishings, floor coverings, building materials, as well as renovation activities, smoking or cooking.

Investigations into the emission-time and/or concentration time behaviour of such VOC have so far been focused mainly on experimental chamber studies (Brown et al. [2], Hodgson and Alevantis [3], Afshari et al. [4], Ellacott and Reed [5], Zhang et al. [6]). However, since real-live situations depend on a variety of factors, theoretical models based on chamber experiments cannot be used to arrive at acceptable generalizations.

Associations between VOC concentration and adverse health effects are not straightforward. Only a few compounds, e.g. formaldehyde or acrolein, activate the biological system by a chemical process directly. Low doses effects of VOC on human health are discussed controversially (Wolkoff et al. [7], Andersson et al. [8], Nielsen et al. [9], Sherriff et al. [10], Herbarth et al. [11]).

Only few threshold levels exist for indoor air pollution. Any health relevance is estimated on the basis of so-called reference values which are derived from environmental-epidemiological studies. A frequently observed fact is that renovation activities increase when a baby is on its way (Herbarth et al. [11]). In fact, it is precisely during pregnancy and early childhood that increased levels of VOC have been found to exert an adverse effect on the health of small children (Sherriff et al. [10], Herbarth et al. [11]). A detailed review (Mendell [12]) compares some current studies which had investigated either the associations between a measured exposure and possible effects or between exposureassociated activities (such as smoking, painting, etc.) and any health risk. Of general importance were those studies which dealt with the health effects found following renovations, as they affected a great number of families (Trevillan et al. [13], Jaakola et al. [14], Diez et al. [15]).

After renovation it is impossible to measure the concentration decay in every apartment or house to decide when a "healthy" indoor environment is reached. That is why it was suggested to examine the time span after finishing renovations when the concentrations have reached again the so-called reference values. The study presented here, will give an indication, for the first time, of the to-beexpected time frame for renovation-derived indoor pollution decreases when the exposure to it will reach a reference level.

\section{Methods}

Passive VOC sampling (marked as EPID, see below) was carried out as part of an epidemiologic longitudinal newborn cohort study for 4 weeks after birth. Children were clinically examined at different time point until the age of 6 years. In addition, parents filled out a detailed questionnaire also concerning renovation activities (detailed study design see Diez et al. [16]). 
As expected the concentration will be decrease faster immediately after renovation than later on active VOC sampling (marked as EXP, see below) (30 minutes, Tenax-Adsorption vials from Sigma-Aldrich Inc.) took place in quick succession in 4 homes and 7 offices daily from day 1 up to day 9 as well as on day 16 and 31, starting immediately following renovations (painting of walls, laying of new wall-to-wall carpeting and new furnishings).

Samples were analysed with capillary-gaschromatography (Autosystem-GC, Perkin Elmer, FID/ECD) (for details see Herbarth et al. [11], Herbarth and Matysik [17]).

26 VOC (hexane, heptane, octane, nonane, decane, undecane, dodecane, tridecane, methylcyclopentane, cyclohexane, methylcyclohexane, benzene, toluene, ethylbenzene, $\mathrm{m}+\mathrm{p}-$ and o-xylene, styrene, 2-, 3-, 4-ethyltoluene, chlorbenzene, trichloroethylene, tetrachlorethylene, $\alpha$ - and $\beta$-pinene, limonene, careen) were summarized to VOCsum. The selection considers a broad spectrum of possible sources (building materials commonly used in renovation activities, furnishing objects, use of common household chemicals) and the selection of others (Molhave et al. [18], Krause et al. [19]).

\section{Results}

The epidemiologic part contained 243 questionnaire- and VOC-measurementbased complete data sets. Of these 90 families pointed out, that none renovations had been undertaken, e.g., no painting, no wall-to-wall carpeting and no new furnishings. From these flats results an average of the VOC-sum-concentration of $202.5 \pm 163.6 \mu \mathrm{g} / \mathrm{m}^{3}$ (reference load - c(ref)).

A relative exposure load was calculated for each measuring point:

$$
c_{r e l}\left(t_{j}\right)=\frac{\frac{\sum_{i=1}^{n} c_{i}\left(t_{j}\right)}{n}}{c(r e f)}
$$

with $\mathrm{t}_{\mathrm{j}}$ - time after renovation, $\mathrm{c}_{\mathrm{i}}$ - concentration at the measurement site (office, home) $\mathrm{i}$,

$\mathrm{n}$ - number of measurements at each measurement site i, c(ref) - reference load $\left(202.5 \mu \mathrm{g} / \mathrm{m}^{3}\right)$.

The range of the VOC sum concentrations determined 1 day following renovations was assessed per home/office as 6 to $12 \mathrm{mg} / \mathrm{m}^{3}$.

Functions were adjusted separately for the measuring points of the epidemiologic (EPID) and experimental study (EXP).

This led to determine that point in time for both functions, from which a value relative to the reference value was to be reached, i.e., the lower limit of the $95^{\text {th }}$ confidence interval of the measured values will cross the upper limit of the $95^{\text {th }}$ confidence interval of the reference value. 


$$
c_{r e l}-\frac{t \cdot s}{\sqrt{n}} \leq c_{r e l}(r e f)+\frac{t \cdot s(r e f)}{\sqrt{n(r e f)}}
$$

$\mathrm{s}=$ standard deviation, $\mathrm{n}=$ number of values, $\mathrm{t}=$ student factor of $\mathrm{n}$ and $\alpha=0.05$ $\left(\mathrm{t}_{\mathrm{n}}, 0.05\right)$

The different goals for indoor air quality determine the time which is necessary to achieve the guideline values (Seifert [20], UBA [21]).

Target value "normal" pollution level (reference load): Using experimental curve (EXP) leads to day 77 (point of intersection), using epidemiological curve (EPID) yielded on day 64 .

Target value $0.3 \mathrm{mg} / \mathrm{m}^{3}$ (no hygienic objections): The time which has to elapse following renovation activities before the guideline value of $0.3 \mathrm{mg} / \mathrm{m}^{3}$ is reached is 27 (EPID) to 51 days (EXP).

Target value $1 \mathrm{mg} / \mathrm{m}^{3}$ : The guideline value of $1 \mathrm{mg} / \mathrm{m}^{3}$ is reached (on condition that no exceeding of single substance reference values has been observed) after a time lag of 2 (EPID) respectively 16 days (EXP).

\section{Discussion}

An important question was answered by this study: What time has to elapse following renovation activities before a "normal" pollution level (reference load) is reached again. "Normal" levels are not reached before the $3^{\text {rd }}$ month after renovations. A minimum wait of 6 weeks is necessary to reach the reference value of $0.3 \mathrm{mg} / \mathrm{m}^{3}$, which characterizes the hygienic "clean-bill-of-health" value and is understood as the ultimate goal (UBA [21], Seifert [20]). Dependent on the different "orientation" criteria of 0.3 and $1 \mathrm{mg} / \mathrm{m}^{3}$ (UBA [21]) the waiting time lies between 2 (experimental curve) and 6 weeks (epidemiologic curve) (Figure 1).

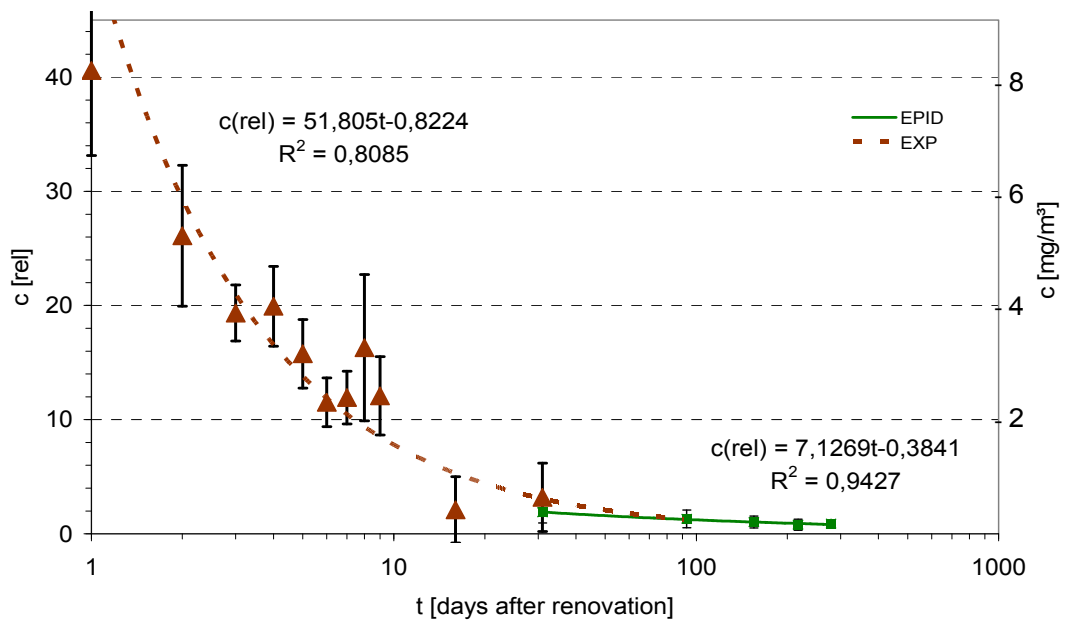

Figure 1: $\quad$ Time course of VOC concentration following renovations. 
The found exponential decay (Figure 1) is in accordance with the TVOC decay in new dwellings (Brown [22]). Our findings confirm this TVOC decay found out by Brown. Brown used one case in Australia. Our results based on a higher number of dwellings (153 in the epidemiological, 11 in the experimental study).

\section{Limitations:}

- Because of geographical, orographical and behaviour specific features a generalization of the findings is limited. Independent from that the applied method allows to derive a concentration-decay-curve and from that a derivation of waiting time.

- The study may be limited due to the selected VOC with different behaviour of the included single substances. A more detailed picture may be smeared using the sum concentration for derivation of the time curve instead of single substances.

Advantages:

- As the random sample, i.e., the number of rooms investigated, is relatively large, it can be assumed that the results are representative for the area under investigation and the influencing factors like ventilation behaviour, different renovation material, different indoor climatic conditions are (related to the mean) representative also.

- The presented study based on the actual measuring of the exposure load in a time-dependent course, starting the active measuring immediately after the "pollution source" ceased for 1 month and followed by passive sampling for another 5 months.

- Deriving the concentration-time-function the VOCsum-concentration are less sensitive in relation to possible changes in individual components, especially since a relatively large number of rooms were tested $(n>100)$.

\section{Conclusions}

The presented methods and results contribute significantly to recommendations for primary prevention measures. Advices should be given considering indoor air pollution and waiting times following renovation activities. These should at least be applicable to public buildings and institutions (especially relevant in case of nurseries, playschools etc.) with increasingly being implemented in private homes as well.

\section{Acknowledgements}

Parts of the study were supported by the State Ministry of Family and Health of Saxony. The authors wish to thank the study participants. We are also indebted to our co-workers of the Study Team for the field work. 
The content (respectively subject matter) of this paper has been published in Indoor Air, 20, pp. 141-146, 2010. The authors thank the publisher WileyBlackwell for the general permission for authors to reuse big parts of the published article.

\section{References}

[1] Molhave, L., Clausen, G., Berglund, B., De Ceaurriz, J., Kettrup, A., Lindvall, T., Maroni, M., Pickering, A.C., Risse, U., Rothweiler, H., Seifert, B., Younes, M., Total Volatile Organic Compounds (TVOC) in Indoor Air Quality Investigations. Indoor Air 7, pp. 225-240, 1997.

[2] Brown, S.K., Cheng, M., Tiganis, B., Mahoney, K.J., VOC and Formaldehyde Emission Measurements for Wattyl low-VOC interior Paint. Report CMIT (C), pp. 445, 2004.

[3] Hodgson, A.T., Alevantis, L., Testing of Building Products for Emissions of Volatile Organic Compounds: Practical Time Point for Assessing Potential Chronic Health Impacts. DHS-Indoor Air Quality Program http://www.cal-iaq.org/VOC/Testing_Practical_Time_Point_ 2004-11-04.pdf. 2004.

[4] Afshari, A., Lundgren, B., Ekberg, L.E., Comparison of three small chamber test methods for the measurement of VOC emission rates from paint. Indoor Air 13, pp. 156-165, 2003.

[5] Ellacott, M.V., Reed, S., Development of Robust Indoor Air Quality Models for the Estimation of Volatile Organic Compound Concentrations in Buildings. Indoor Built Environment, 8, pp. 345-360, 1999.

[6] Zhang, J.S., Zhang, J.S., Chen, Q., Yang, X., A critical review on studies of volatile organic compound (VOC) sorption on building materials. ASHRAE Transactions, 108(1), pp. 162-174, 2002.

[7] Wolkoff, P., Clausen, P.A., Jensen, B., Nielsen, G.D., Wilkins, C.K., Are We Measuring the Relevant Indoor Pollutants?. Indoor Air, 7, pp. 92-106, 1997.

[8] Andersson, K., Bakke, J.V., Bjørseth, O., Bornehag, C.G., Clausen, G., Hongslo, J.K., Kjellman, M., Kjærgaard, S., Levy, F., Mølhave, L., Skerfving, S., Sundell, J., TVOC and Health in Non-Industrial Indoor Environments, Indoor Air 7, pp. 78-91, 1997.

[9] Nielsen, G.D., Larsen, S.T., Olsen, O., Løvik, M., Poulsen, L.K., Glue, C., Wolkoff, P., Do Indoor chemicals promote development of airway allergy? Indoor Air 17, pp. 236-255, 2007.

[10] Sherriff, A., Farrow, A., Golding, J., Henderson, J., the ALSPAC study team. Frequent use of chemical household products is associated with persistent wheezing in pre-school age children. Thorax, 60, pp. 45-49, 2005.

[11] Herbarth, O., Fritz, G.J., Rehwagen, M., Richter, M., Röder, S., Schlink, U., Association between indoor renovation activities and eczema in early childhood. Int J Hyg Env Health, 209(3), pp. 241-247, 2006. 
[12] Mendell, M.J., Indoor residential chemical emissions as risk factors for respiratory and allergic effects in children: a review. Indoor Air 17(4), pp. 259-277, 2007.

[13] Trevillian, L.F., Ponosby, A.L., Dwyer, T., Kemp, A., Cochrane, J., Lim, L.L., Carmichael, A., Infant sleeping environment and asthma at 7 years: a prospective cohort study. Am. J. Public Health, 95, pp. 2238-2245, 2005.

[14] Jaakkola, J.J., Parise, H., Kislitsin, V., Lebedeva, N.I., Spengler, J.D., Asthma, wheezing, and allergies in Russian schoolchildren in relation to new surface materials in the home. Am. J. Public Health, 94, pp. 660-662, 2004.

[15] Diez, U., Rehwagen, M., Rolle-Kampzcyk, U., Wetzig, H., Schulz, R., Richter, M., Lehmann, I., Borte, M., Herbarth, O., Redecoration of apartments promotes obstructive bronchitis in atopy risk infants - results of the LARS Study. Int. J. Hyg. Environ. Health, 206, pp. 173-179, 2003.

[16] Diez, U., Kroessner, T., Rehwagen, M., Richter, M., Wetzig, H., Schulz, R., Borte, M., Metzner, G., Krumbiegel, P., Herbarth, O., Effect of indoor painting and smoking on airway symptoms in atopy risk children in the first year of life - results of the LARS-study. Int. J Hyg. Environ. Health, 203, pp. 23-28, 2000.

[17] Herbarth, O. and Matysik, S., Decreasing concentrations of volatile organic compounds (VOC) emitted following home renovations. Indoor Air, 20, pp. 141-146, 2010.

[18] Molhave, L., Bach, B., Pedersen, O.F., Human reactions to low concentrations of volatile organic compounds. Environ Int 12, pp. 167-175, 1986.

[19] Krause, C., Chutsch, M., Henke, M., Huber, M., Kliem, C., Leiske, M., Mailahn, W., Schulz, C., Schwarz, E., Seifert, B., Ullrich, D., UmweltSurvey Bd IIIc Wohn-Innenraum: Raumluft (Environmental Survey Vol IIIc Indoor conditions in apartments: Indoor Air Quality). WaBoLuhefte 4/1991. ISSN 0175-4211 ISBN 3-89254-104-3, 1991.

[20] Seifert B. Richtwerte für die Innenraumluft - Die Beurteilung der Innenraumluftqualität mit Hilfe der Summe der flüchtigen organischen Verbindungen (TVOC-Wert). Bundesgesundheitsbl - GesundheitsforschGesundheitsschutz, 3, 270-278. 1999.

[21] UBA. Beurteilung von Innenraumluftkonzentrationen mittels Referenz- und Richtwerten. (Evaluation of indoor air contaminants by means of reference and guideline values). Bundesgesundheitsbl - Gesundheitsforsch Gesundheitsschutz, 7, pp. 993-1005, 2007.

[22] Brown, S.K., Volatile Organic Pollutants in New and Established Buildings in Melbourne, Australia. Indoor Air, 12, 55-63, 2002. 